\title{
Time evolution of an aluminogermanate zeolite synthesis: segregation of two closely similar phases with the same structure type
}

\author{
Luis A. Villaescusa and Miguel A. Camblor \\ Supporting Information
}

\section{Contents}

1 Rietveld refinements $\quad 10$

$\begin{array}{lll}2 & \text { References } & 17\end{array}$

\section{List of Figures}

S1 Unit cell volume of $\mathrm{GeO}_{2}-\mathrm{AST}$ phases vs the Connolly volume of their occluded cations . . . . . 3

S2 Powder XRD of the GeAl20-y series (from bottom to top, $\mathrm{y}=1,4,9,15,30$ ). The bottom and top ticks mark allowed reflections in space group $I 4 m$ for $\mathrm{GeO}_{2}$-AST and GeAl9-30, respectively

S3 ${ }^{1} \mathrm{H}$ NMR in solution of as-made AST samples dissolved in $\mathrm{NaOD} / \mathrm{D}_{2} \mathrm{O}$. From bottom to top: $\mathrm{GeO}_{2}$-AST and GeAl9-1, GeAl9-9, GeAl9-16 and GeAl9-30. Signals marked with * around 1 and $3 \mathrm{ppm}$ correspond to tetraethylammonium added as an internal standard for quantification . . .

S4 ${ }^{1} \mathrm{H}$ NMR of solutions containing $\mathrm{GeO}_{2}$ and tMAHCl (top) or TMACl (bottom) in $\mathrm{NaOD} / \mathrm{D}_{2} \mathrm{O}$. Signals marked with * around 1 and $3 \mathrm{ppm}$ correspond to tetraethylammonium added as an internal standard for quantification . . . . . . . . . . . . . . . .

S5 XRD pattern of a $\mathrm{GeO}_{2}$ AST phase synthesized directly with TMA cations and fluoride anions. The lower ticks mark allowed reflections in space group $I 4 m$ for the TMA-containing GeAl9-30 .

S6 ${ }^{1} \mathrm{H}$ (top) and ${ }^{13} \mathrm{C}$ (bottom) NMR spectra after reaction of a equimolar mixture of TMTBA and tMA in water at neutral $\mathrm{pH}$ for 7 days at $150{ }^{\circ} \mathrm{C}$. The spectra were recorded at basic $\mathrm{pH}$ after addition of NaOD. Signals marked with * were also observed in a blank control reaction with no TMTBA added under otherwise identical conditions (all the reactions were carried out in brand new teflon liners). ${ }^{13} \mathrm{C}$ signals at 30 and $45 \mathrm{ppm}$ and the ${ }^{1} \mathrm{H}$ signal around $1 \mathrm{ppm}$ have not been

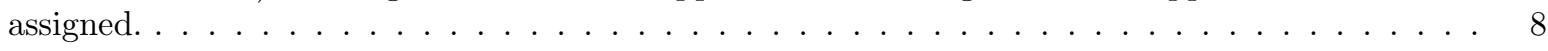

S7 FESEM image of as-made $\mathrm{GeO}_{2}-\mathrm{AST} \ldots \ldots \ldots \ldots \ldots \ldots$

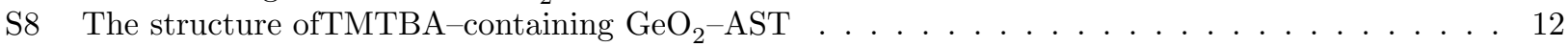

S9 Rietveld plot for TBTMAF-containing $\mathrm{GeO}_{2}-\mathrm{AST}$. Experimental (crosses), calculated (solid line), and difference plot (lower trace). The tick marks represent the positions of allowed reflec-

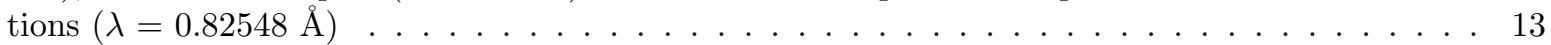

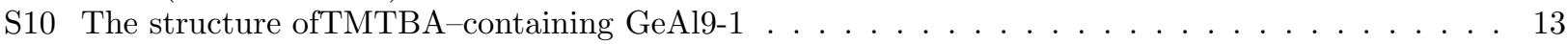

S11 Rietveld plot for TMTBA-containing GeAl9-1. Experimental (crosses), calculated (solid line), and difference plot (lower trace). The tick marks represent the positions of allowed reflections $(\lambda$

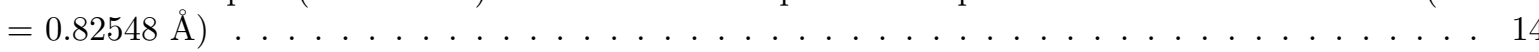


S12 The structure of TMAF-containing GeAl9-30 . . . . . . . . . . . . . . . . . . . . 14

S13 Rietveld plot for TMAF-containing GeAl9-30. Experimental (crosses), calculated (solid line), and difference plot (lower trace). The tick marks represent the positions of allowed reflections $(\lambda$ $=0.82548 \AA) \ldots \ldots \ldots \ldots \ldots \ldots \ldots \ldots \ldots \ldots \ldots \ldots$

S14 FE-SEM images of crystals of GeAl9-30 that are either broken or properly oriented to show they are hollow. Please, note the very thick walls. . . . . . . . . . . . . . . . . 15

S15 FE-SEM images of a crystal of GeAl9-30 after focused Ga ion bombardment (ZEISS AURIGA Compact). The sputtering level increases in the sequence of figures from left to right and from top to bottom. . . . . . . . . . . . . . . . . . . . . . . . . 16

S16 Powder XRD of $\mathrm{GeO}_{2}-\mathrm{AST}$ zeolites prepared from crystallization gels containing TMA/(TMA+TMTBA) molar fractions of (from bottom to top): $0.5,0.475,0.45,0.4,0.2,0.1$ and 0 , showing no phase seggregation occurred when TMA and TMTBA can simultaneously act as SDA. Weak reflections corresponding to quartz-like $\mathrm{GeO}_{2}$ impurities are marked with * . . . . . . . . . . . . . . 16

\section{List of Tables}

S1 Crystallographic and Experimental Parameters for the Rietveld Refinement of as-made $\mathrm{GeO}_{2}-$ AST, GeAl9-1 and GeAl9-30 . . . . . . . . . . . . . . . . . . . . . . . 10

S2 Fractional atomic coordinates, isotropic displacement parameters and fraccional occupancies for as-made $\mathrm{GeO}_{2}-\mathrm{AST}$ in space group $I 4 / m \ldots \ldots$. . . . . . . . . . . . . . . . . . . . . 11

S3 Fractional atomic coordinates, isotropic displacement parameters and fraccional occupancies for as-made GeAl9-1 in space group $I 4 / m \ldots \ldots$. . . . . . . . . . . . . . . . . . . . . 11

S4 Fractional atomic coordinates, isotropic displacement parameters and fraccional occupancies for

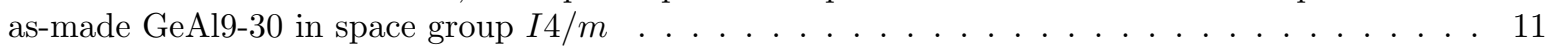

S5 Distances $(\AA)$ and angles $\left(^{\circ}\right)$ in $\mathrm{GeO}_{2}-\mathrm{AST}, \mathrm{GeAl9}-1$ and GeAl9-30 . . . . . . . . . . . . . . . . . 12 


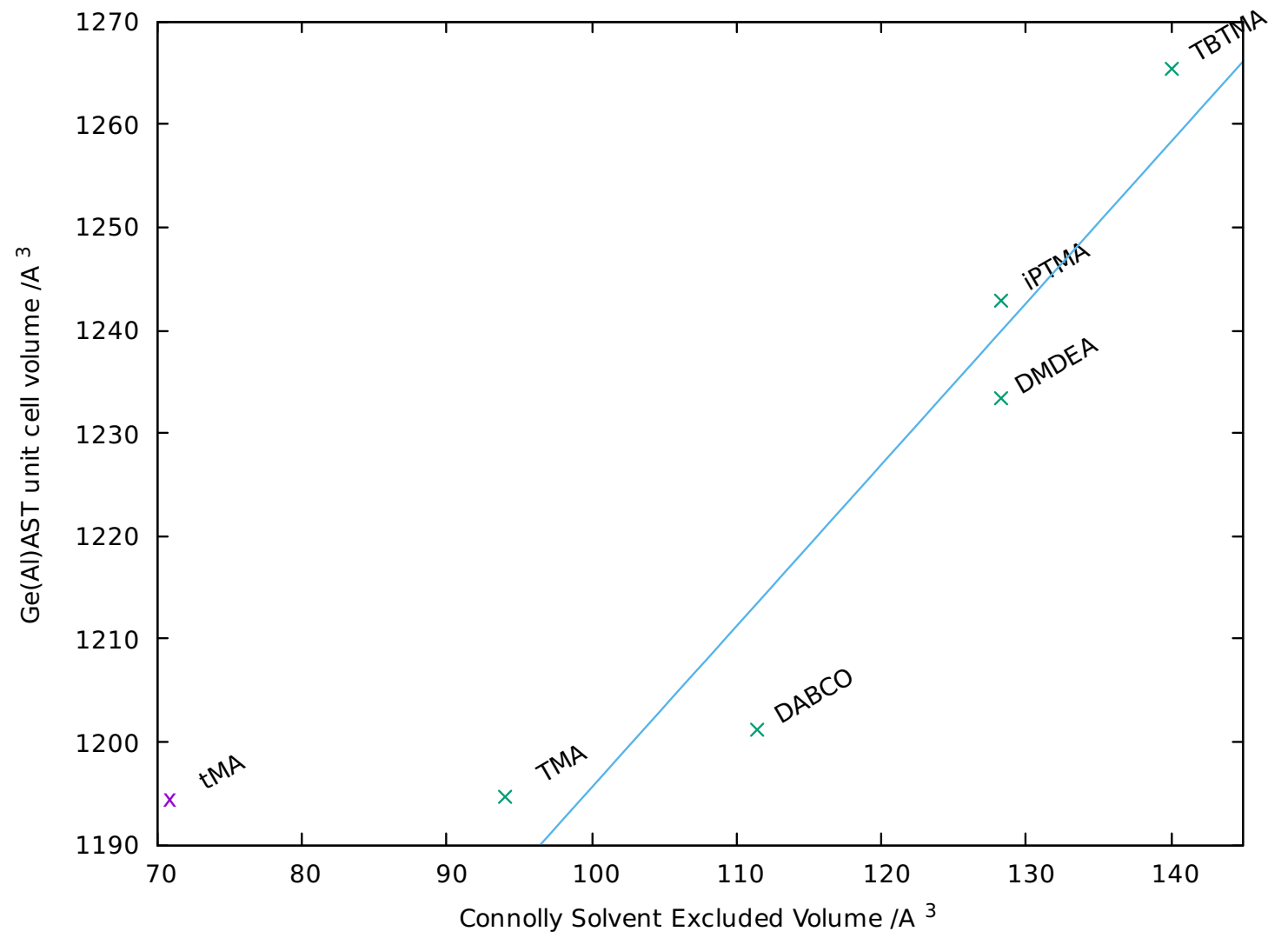

Figure S1: Unit cell volume of $\mathrm{GeO}_{2}-\mathrm{AST}$ phases vs the Connolly volume of their occluded cations 


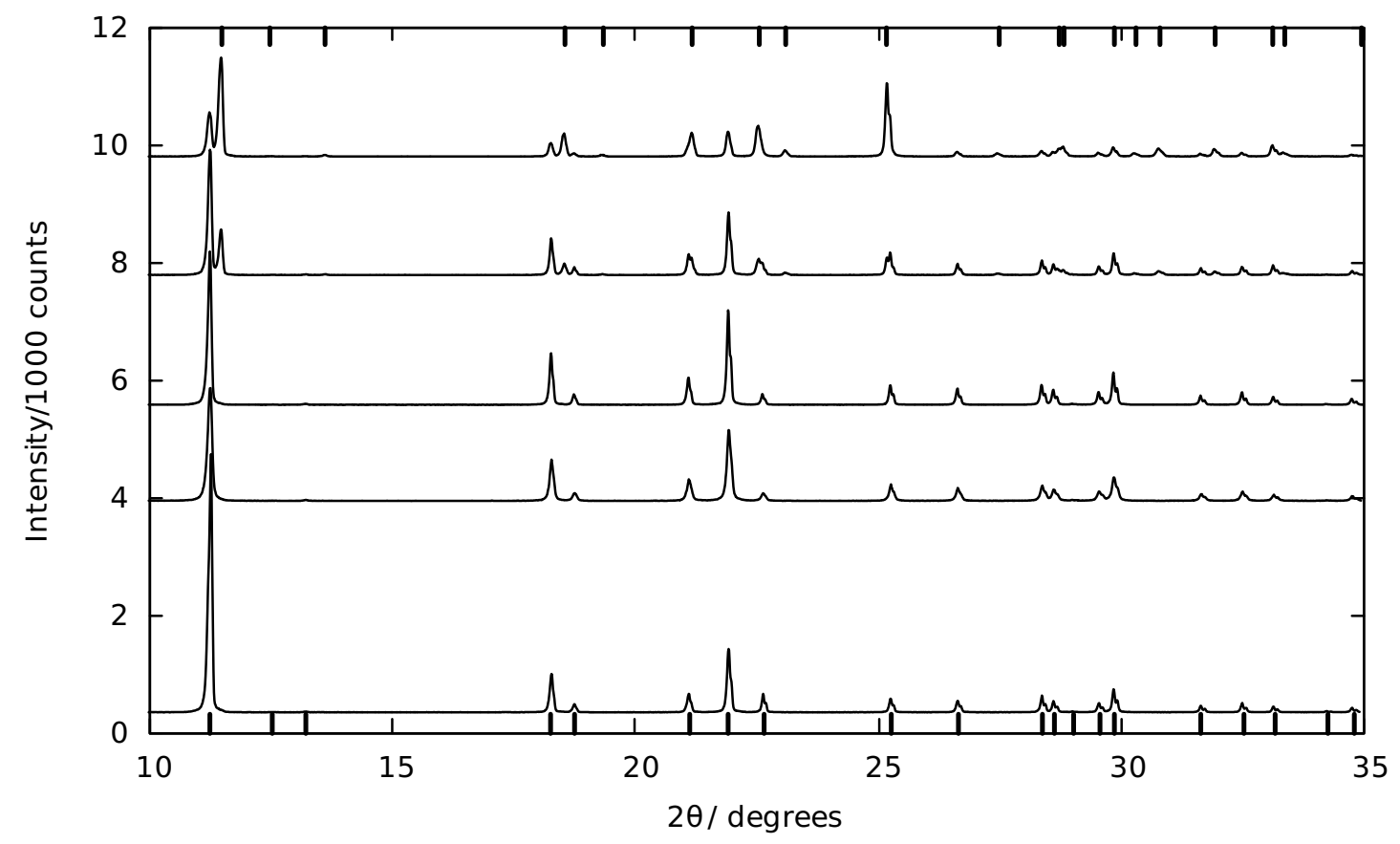

Figure S2: Powder XRD of the GeAl20-y series (from bottom to top, $\mathrm{y}=1,4,9,15,30$ ). The bottom and top ticks mark allowed reflections in space group $I 4 m$ for $\mathrm{GeO}_{2}$-AST and GeAl9-30, respectively 


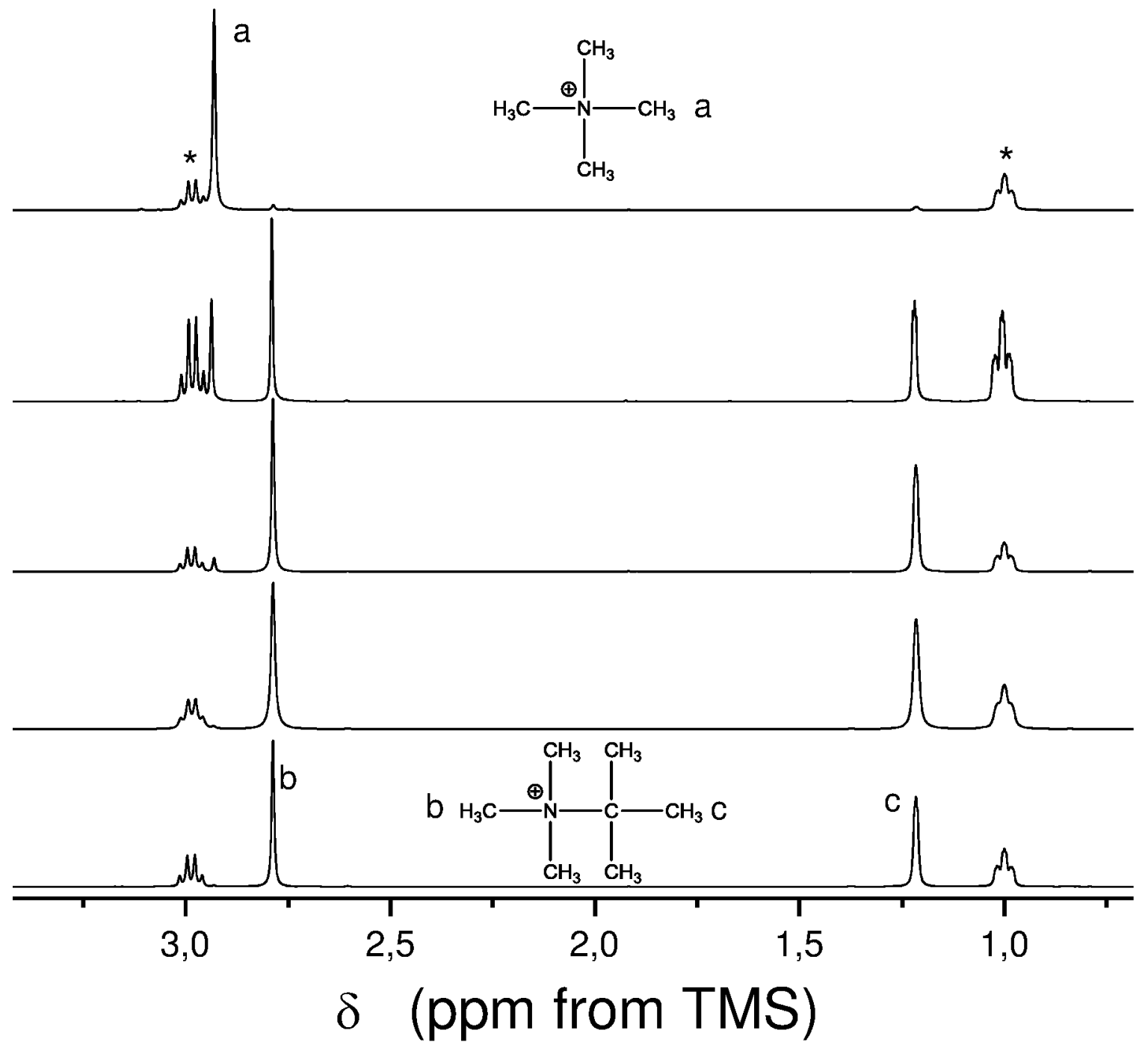

Figure S3: ${ }^{1} \mathrm{H}$ NMR in solution of as-made AST samples dissolved in $\mathrm{NaOD} / \mathrm{D}_{2} \mathrm{O}$. From bottom to top: $\mathrm{GeO}_{2^{-}}$ AST and GeAl9-1, GeAl9-9, GeAl9-16 and GeAl9-30. Signals marked with * around 1 and 3 ppm correspond to tetraethylammonium added as an internal standard for quantification 


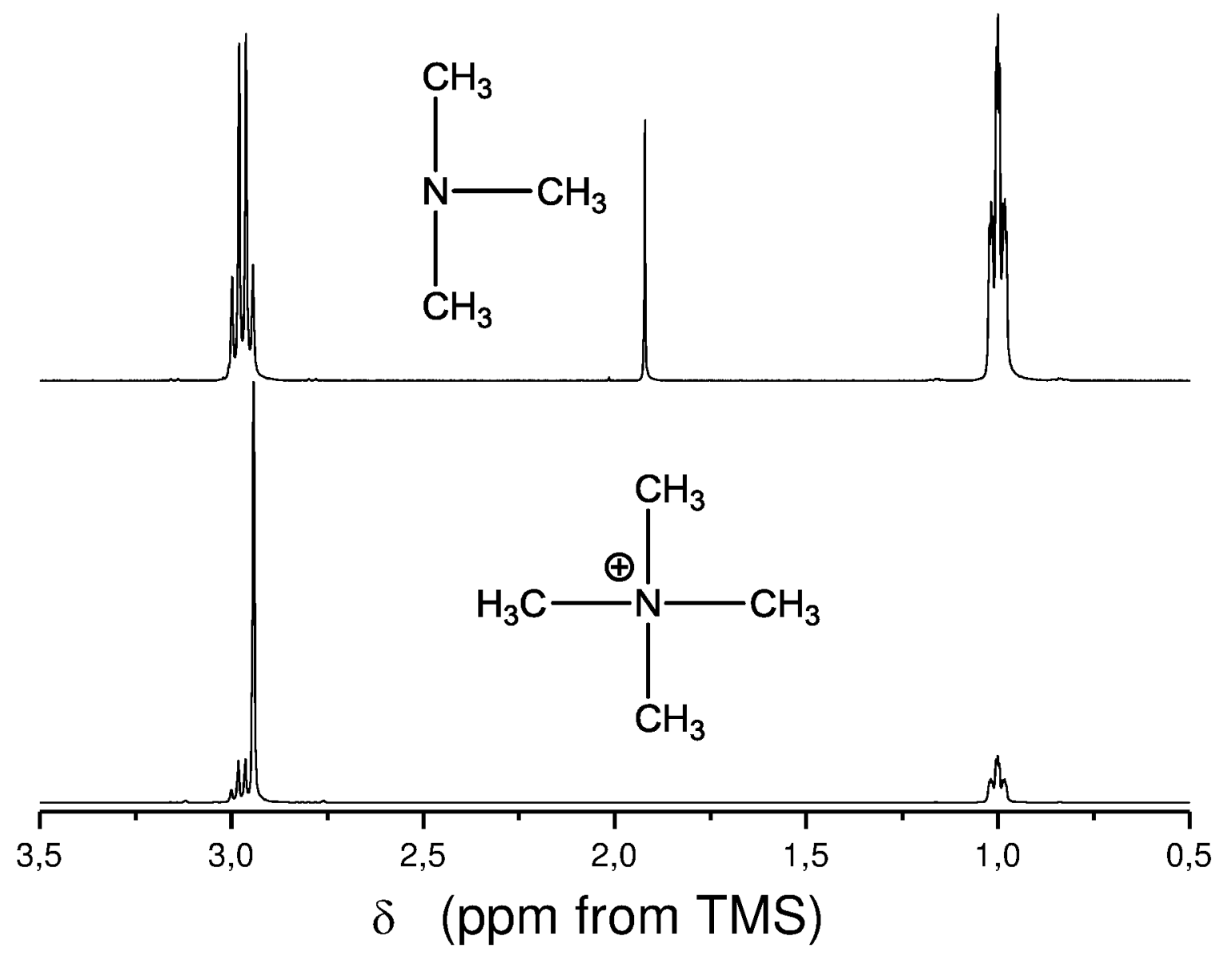

Figure S4: ${ }^{1} \mathrm{H}$ NMR of solutions containing $\mathrm{GeO}_{2}$ and tMAHCl (top) or TMACl (bottom) in NaOD/ $\mathrm{D}_{2} \mathrm{O}$. Signals marked with ${ }^{*}$ around 1 and $3 \mathrm{ppm}$ correspond to tetraethylammonium added as an internal standard for quantification 


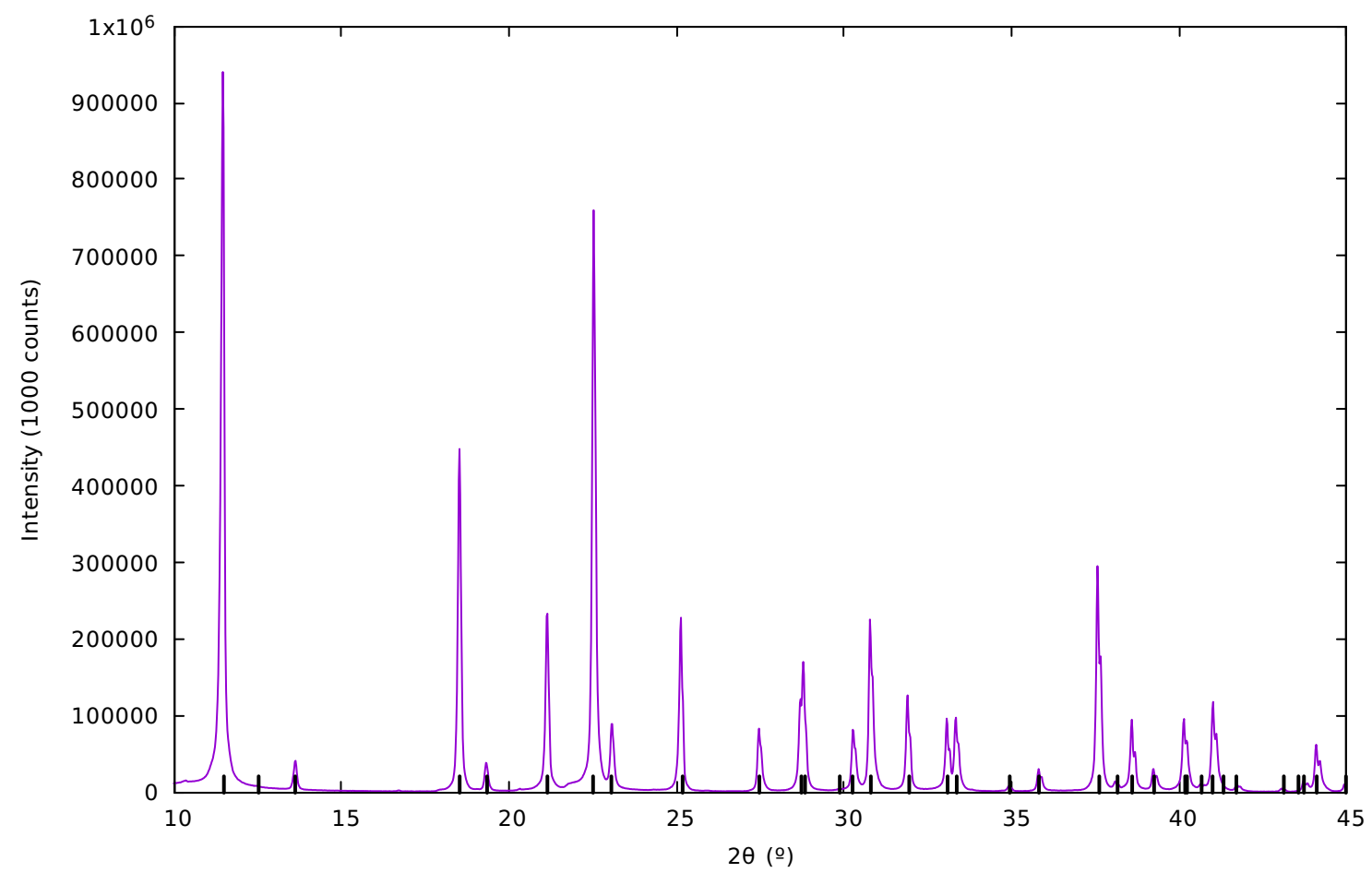

Figure S5: XRD pattern of a $\mathrm{GeO}_{2}$ AST phase synthesized directly with TMA cations and fluoride anions. The lower ticks mark allowed reflections in space group $I 4 m$ for the TMA-containing GeAl9-30 


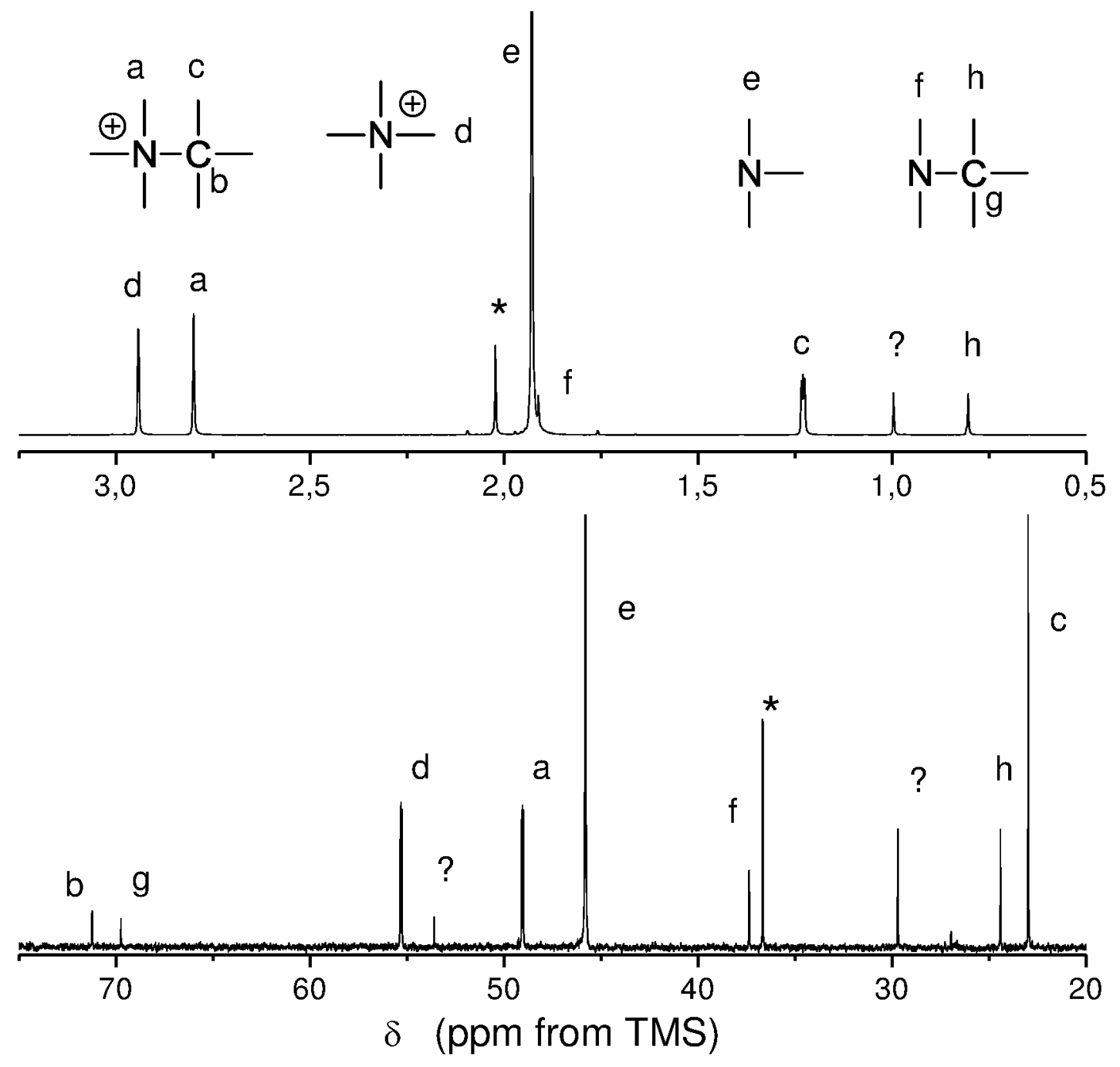

Figure S6: ${ }^{1} \mathrm{H}$ (top) and ${ }^{13} \mathrm{C}$ (bottom) NMR spectra after reaction of a equimolar mixture of TMTBA and tMA in water at neutral $\mathrm{pH}$ for 7 days at $150{ }^{\circ} \mathrm{C}$. The spectra were recorded at basic $\mathrm{pH}$ after addition of NaOD. Signals marked with ${ }^{*}$ were also observed in a blank control reaction with no TMTBA added under otherwise identical conditions (all the reactions were carried out in brand new teflon liners). ${ }^{13} \mathrm{C}$ signals at 30 and $45 \mathrm{ppm}$ and the ${ }^{1} \mathrm{H}$ signal around $1 \mathrm{ppm}$ have not been assigned. 


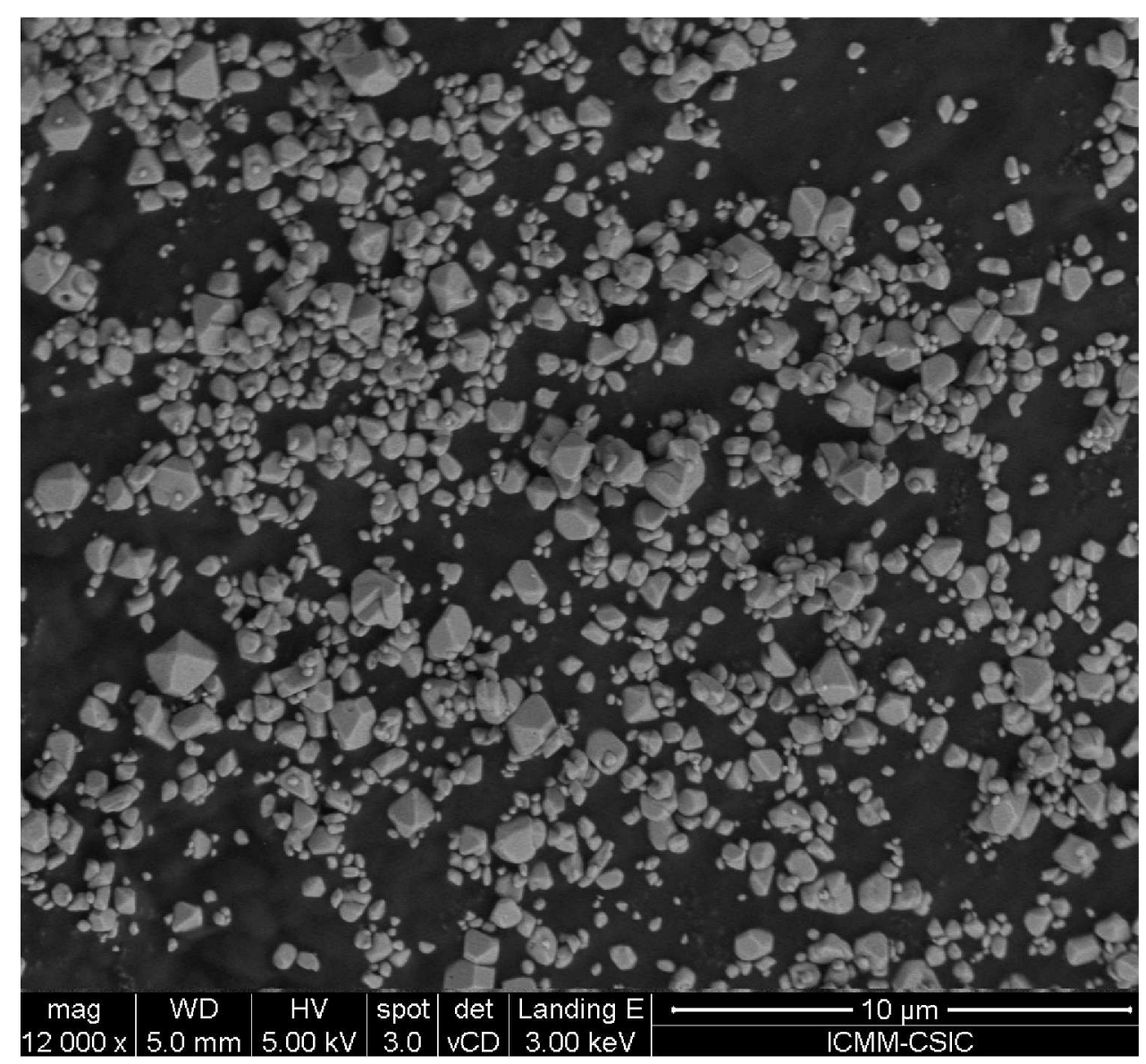

Figure S7: FESEM image of as-made $\mathrm{GeO}_{2}-\mathrm{AST}$ 


\section{Rietveld refinements}

The synchrotron patterns were indexed as tetragonal with systematic extinctions consistent with the space group reported for the TMTBA-containing silica version $(I 4 / m)^{1}$. Hence, for each phase a model in $I 4 / m$ with only Ge and $\mathrm{O}$ and with the corresponding unit cell edges were first introduced into the refinement. Given the proximity of $\lambda$ to the K-edge of Ge at $\lambda=0.89557 \AA$ anomalous dispersion and absorption correction were introduced in the refinement. For the absorption correction, the Lobanov and alte da Veiga function implemented in GSAS was used, ${ }^{2}$ with overall $\mu$ values determined using the utility in the Argonne National Laboratory web site (http://11bm.xray.aps.anl.gov/absorb/absorb.php) from each component linear coefficients and assuming a packing factor of $0.6\left(\mu^{*} \mathrm{R}=4.60\right.$ and 5.46 for $\mathrm{GeO}_{2}-\mathrm{AST}$ and GeAl9-30, respectively, and 4.53 for GeAl91). Real and imaginary anomalous scattering factors given by the same web, which were identical to those determined by fprime ${ }^{3}$, were introduced into the refinement. The scale factor, unit cell, zero error, background (Shifted Chebyshev with 18 coefficients, then 20, then 15 for GeAl9-1) and profile coefficients $\left({ }^{4}\right)$ were refined before introducing $\mathrm{F}$ in the special position inside the $\mathrm{D} 4 \mathrm{R}$ units and the cation as a rigid body in the bigger cavity, with fractional occupancies to account for one cation per cage (and for $\mathrm{C}$ in methyl groups accounting for all the $\mathrm{H}$ bonded to it, i.e. rather than $1 \mathrm{C}$ each methyl is 1.5C (9 electrons in $\mathrm{CH} 3$ compared to 6 in $\mathrm{C}$ ). Then, the framework atomic positions were refined and then the rigid body allowed to move. Finally, isotropic atomic displacement parameters were refined, with the restriction that all the atoms in the cation should have the same isotropic factors. In GeAl9-1 Al was introduced equally distributed among both crystallographic sites and the fractional factors of $\mathrm{Al}, \mathrm{Ge}$ and $\mathrm{F}$ adjusted to account for the chemical composition. Attempts to refine fractional occupancies of $\mathrm{Ge}$ and $\mathrm{Al}$, aimed to determine the possibility of $\mathrm{Al}$ preferential distribution, failed probably due to the small concentration of $\mathrm{Al}$. In the final models the four symmetrically equivalent cations in each cavity, with positive isotropic parameters, are assumed to represent disorder. Crystallographic data are collected in Table S1 and atomic parameters in Tables S2m S3 and S4. The structure is represented in Figures S8, S10 and S12 and the final Rietveld plots are shown in Figures S9, S11 and S13.

Table S1: Crystallographic and Experimental Parameters for the Rietveld Refinement of as-made $\mathrm{GeO}_{2}-\mathrm{AST}_{\text {, }}$ GeAl9-1 and GeAl9-30

\begin{tabular}{|c|c|c|c|}
\hline material & $\mathrm{GeO}_{2}-\mathrm{AST}$ & GeAl9-1 & GeAl9-30 \\
\hline composition & $\mathrm{C}_{14} \mathrm{~N}_{2} \mathrm{~F}_{2} \mathrm{Ge}_{20} \mathrm{O}_{40}$ & $\mathrm{C}_{14} \mathrm{~N}_{2} \mathrm{~F}_{1.635} \mathrm{Al}_{0.365} \mathrm{Ge}_{19.635} \mathrm{O}_{40}$ & $\mathrm{C}_{8} \mathrm{~N}_{2} \mathrm{~F}_{2} \mathrm{Ge}_{20} \mathrm{O}_{40}$ \\
\hline wavelength $(\AA)$ & 0.82548 & 0.82548 & 0.82548 \\
\hline temperature $(\mathrm{K})$ & 293 & 293 & 293 \\
\hline $2 \theta$ range & $3.98 / 63.98$ & $3.98 / 63.98$ & $4.00 / 56.520$ \\
\hline no. of data points & 6001 & 6001 & 5254 \\
\hline no. of reflections & 738 & 734 & 500 \\
\hline $\begin{array}{l}\text { Space Group } \\
\text { unit cell parameters }(\AA)\end{array}$ & $I 4 / m$ & $I 4 / m$ & $I 4 / m$ \\
\hline$a, b$ & $9.46471(11)$ & $9.46246(10)$ & $9.18227(10)$ \\
\hline$c$ & $14.10195(22)$ & $14.12772(23)$ & $14.15017(17)$ \\
\hline Cell volume $\left(\AA^{3}\right)$ & $1263.26(4)$ & $1264.97(4)$ & $1193.060(32)$ \\
\hline \multicolumn{4}{|l|}{ Residuals $^{a}$} \\
\hline $\mathrm{R}_{w p}$ & 3.36 & 3.85 & 3.25 \\
\hline $\mathrm{R}_{p}$ & 2.10 & 2.38 & 2.29 \\
\hline $\mathrm{R}_{F^{2}}$ & 13.60 & 13.73 & 14.76 \\
\hline reduced $\chi^{2}$ & 11.67 & 1.767 & 1.976 \\
\hline
\end{tabular}


Table S2: Fractional atomic coordinates, isotropic displacement parameters and fraccional occupancies for as-made $\mathrm{GeO}_{2}-\mathrm{AST}$ in space group $I 4 / m$

\begin{tabular}{llllll}
\hline atom & $\mathrm{x}$ & $\mathrm{y}$ & $\mathrm{z}$ & Occupancy & Uiso \\
$\mathrm{Ge} 1$ & $0.45053(24)$ & $0.26869(21)$ & $0.88741(12)$ & $1.000(0)$ & $0.02981(33)$ \\
$\mathrm{Ge} 2$ & $0.5000000(0)$ & $0.0000000(0)$ & $0.7500000(0)$ & $1.000(0)$ & $0.02981(33)$ \\
$\mathrm{O} 3$ & $0.4107(15)$ & $0.1286(13)$ & $0.8191(7)$ & $1.000(0)$ & $0.0465(25)$ \\
O4 & $0.3274(12)$ & $0.3885(13)$ & $0.8611(7)$ & $1.000(0)$ & $0.0465(25)$ \\
O5 & $0.2853(15)$ & $-0.0624(21)$ & $0.5000000(0)$ & $1.000(0)$ & $0.0465(25)$ \\
$\mathrm{F}$ & $0.5000000(0)$ & $0.5000000(0)$ & $0.0000000(0)$ & $1.000(0)$ & $0.066(10)$ \\
$\mathrm{C} 1$ & $0.4985(27)$ & $0.4527(18)$ & $0.5465(9)$ & $0.125(0)$ & $0.212(17)$ \\
$\mathrm{C} 2$ & $0.649(5)$ & $0.435(6)$ & $0.5856(31)$ & $0.188(0)$ & $0.212(17)$ \\
$\mathrm{C} 3$ & $0.437(6)$ & $0.3060(21)$ & $0.523(4)$ & $0.188(0)$ & $0.212(17)$ \\
$\mathrm{C} 4$ & $0.406(6)$ & $0.524(6)$ & $0.6225(20)$ & $0.188(0)$ & $0.212(17)$ \\
$\mathrm{C} 5$ & $0.355(5)$ & $0.568(6)$ & $0.4121(30)$ & $0.188(0)$ & $0.212(17)$ \\
$\mathrm{C} 6$ & $0.561(6)$ & $0.6936(22)$ & $0.473(4)$ & $0.188(0)$ & $0.212(17)$ \\
$\mathrm{C} 7$ & $0.592(6)$ & $0.482(6)$ & $0.3761(20)$ & $0.188(0)$ & $0.212(17)$ \\
$\mathrm{N}$ & $0.5015(27)$ & $0.5473(18)$ & $0.4535(9)$ & $0.125(0)$ & $0.212(17)$ \\
\hline \hline
\end{tabular}

Table S3: Fractional atomic coordinates, isotropic displacement parameters and fraccional occupancies for as-made GeAl9-1 in space group $I 4 / m$

\begin{tabular}{llllll}
\hline atom & $\mathrm{x}$ & $\mathrm{y}$ & $\mathrm{z}$ & Occupancy & Uiso \\
GE1 & $0.45072(10)$ & $0.26785(10)$ & $0.88692(10)$ & $0.982(0)$ & $0.982(0)$ \\
GE2 & $0.5000000(0)$ & $0.0000000(0)$ & $0.7500000(0)$ & $0.982(0)$ & $0.982(0)$ \\
O3 & $0.4244(15)$ & $0.1189(11)$ & $0.8183(7)$ & $1.000(0)$ & $1.000(0)$ \\
O4 & $0.3299(12)$ & $0.3772(11)$ & $0.8639(7)$ & $1.000(0)$ & $1.000(0)$ \\
O5 & $0.2981(13)$ & $-0.0591(19)$ & $0.5000000(0)$ & $1.000(0)$ & $1.000(0)$ \\
F6 & $0.0000000(0)$ & $0.0000000(0)$ & $0.5000000(0)$ & $0.817(0)$ & $0.817(0)$ \\
C8 & $0.474(6)$ & $0.429(8)$ & $0.545(4)$ & $0.125(0)$ & $0.125(0)$ \\
C9 & $0.518(7)$ & $0.445(8)$ & $0.441(5)$ & $0.188(0)$ & $0.188(0)$ \\
C10 & $0.535(6)$ & $0.290(10)$ & $0.584(6)$ & $0.188(0)$ & $0.188(0)$ \\
C11 & $0.537(11)$ & $0.554(11)$ & $0.602(6)$ & $0.188(0)$ & $0.188(0)$ \\
C12 & $0.259(11)$ & $0.414(7)$ & $0.656(6)$ & $0.188(0)$ & $0.188(0)$ \\
C13 & $0.243(9)$ & $0.565(8)$ & $0.516(8)$ & $0.188(0)$ & $0.188(0)$ \\
C14 & $0.241(6)$ & $0.308(8)$ & $0.499(6)$ & $0.188(0)$ & $0.188(0)$ \\
N15 & $0.307(6)$ & $0.429(6)$ & $0.554(5)$ & $0.125(0)$ & $0.125(0)$ \\
Al1 & $0.45072(10)$ & $0.26785(10)$ & $0.88692(10)$ & $0.018(0)$ & $0.018(0)$ \\
Al2 & $0.500000(0)$ & $0.0000000(0)$ & $0.7500000(0)$ & $0.018(0)$ & $0.018(0)$ \\
\hline \hline
\end{tabular}

Table S4: Fractional atomic coordinates, isotropic displacement parameters and fraccional occupancies for as-made GeAl9-30 in space group $I 4 / m$

\begin{tabular}{llllll}
\hline atom & $\mathrm{x}$ & $\mathrm{y}$ & $\mathrm{z}$ & Occupancy & Uiso \\
Ge1 & $0.44063(25)$ & $0.26445(23)$ & $0.88828(11)$ & $1.0000(0)$ & $0.0539(5)$ \\
Ge2 & 0.5 & 0.0 & 0.75 & $1.0000(0)$ & $0.0539(5)$ \\
O3 & $0.4073(14)$ & $0.1161(11)$ & $0.8259(6)$ & $1.0000(0)$ & $0.0662(25)$ \\
O4 & $0.3175(11)$ & $0.3898(13)$ & $0.8628(6)$ & $1.0000(0)$ & $0.0662(25)$ \\
O5 & $0.2798(14)$ & $-0.0741(17)$ & 0.5 & $1.0000(0)$ & $0.0662(25)$ \\
F6 & 0.5 & 0.5 & 0.0 & $1.0000(0)$ & $0.117(12)$ \\
N7 & $0.4009(32)$ & $0.521(4)$ & $0.4531(19)$ & $0.1250(0)$ & $0.034(10)$ \\
C8 & $0.257(4)$ & $0.495(4)$ & $0.5026(29)$ & $0.1875(0)$ & $0.034(10)$ \\
C9 & $0.523(4)$ & $0.522(8)$ & $0.5253(25)$ & $0.1875(0)$ & $0.034(10)$ \\
C10 & $0.428(5)$ & $0.400(5)$ & $0.3822(30)$ & $0.1875(0)$ & $0.034(10)$ \\
C11 & $0.396(6)$ & $0.666(4)$ & $0.402(4)$ & $0.1875(0)$ & $0.034(10)$ \\
\hline \hline
\end{tabular}


Table S5: Distances $(\AA)$ and angles $\left(^{\circ}\right)$ in $\mathrm{GeO}_{2}-\mathrm{AST}$, GeAl9-1 and GeAl9-30

\begin{tabular}{llll}
\hline & GeAST & GeAl9-1 & GeAl9-30 \\
\hline Ge1-O3 & $1.682(11)$ & $1.729(10)$ & $1.652(10)$ \\
Ge1-O4 & $1.668(12)$ & $1.576(12)$ & $1.653(12)$ \\
Ge1-O4 & $1.664(12)$ & $1.761(11)$ & $1.670(11)$ \\
Ge1-O5 & $1.673(4)$ & $1.718(4)$ & $1.638(4)$ \\
average Ge1 & 1.672 & 1.696 & 1.653 \\
Ge1-F & $2.7446(19)$ & $2.7559(17)$ & $2.7339(18)$ \\
Ge2-O3 (x4) & $1.774(11)$ & $1.645(9)$ & $1.736(9)$ \\
Ge1-Ge1 (x2) & $3.1661(28)$ & $3.1758(16)$ & $3.1545(30)$ \\
Ge1-Ge1 & $3.1755(35)$ & $3.1950(28)$ & $3.1616(32)$ \\
Ge1-Ge2 (x4) & $3.2313(19)$ & $3.2223(14)$ & $3.1658(18)$ \\
average Ge-Ge & 3.1941 & 3.1922 & 3.1604 \\
O3-Ge1-O4 & $104.6(6)$ & $108.4(6)$ & $109.3(5)$ \\
O3-Ge1-O4 & $109.9(6)$ & $107.5(6)$ & $107.3(6)$ \\
O3-Ge1-O5 & $106.6(6)$ & $102.6(5)$ & $107.2(6)$ \\
O4-Ge1-O4 & $111.3(7)$ & $114.4(6)$ & $112.8(7)$ \\
O4-Ge1-O5 & $111.6(7)$ & $113.1(7)$ & $109.1(6)$ \\
O4-Ge1-O5 & $112.4(7)$ & $110.1(6)$ & $110.9(6)$ \\
average O-Ge1-O & 109.40 & 109.35 & 109.43 \\
O3-Ge2-O3 (x2) & $113.3(7)$ & $108.2(7)$ & $103.6(6)$ \\
O3-Ge2-O3 (x4) & $107.58(35)$ & $110.1(4)$ & $112.49(30)$ \\
average O-Ge2-O & 109.49 & 109.47 & 109.53 \\
Ge1-O3-Ge2 & $138.5(9)$ & $145.4(9)$ & $138.2(8)$ \\
Ge1-O4-Ge1 & $143.7(7)$ & $144.2(7)$ & $143.3(6)$ \\
Ge1-O5-Ge1 & $143.3(9)$ & $136.9(8)$ & $149.7(9)$ \\
\hline
\end{tabular}
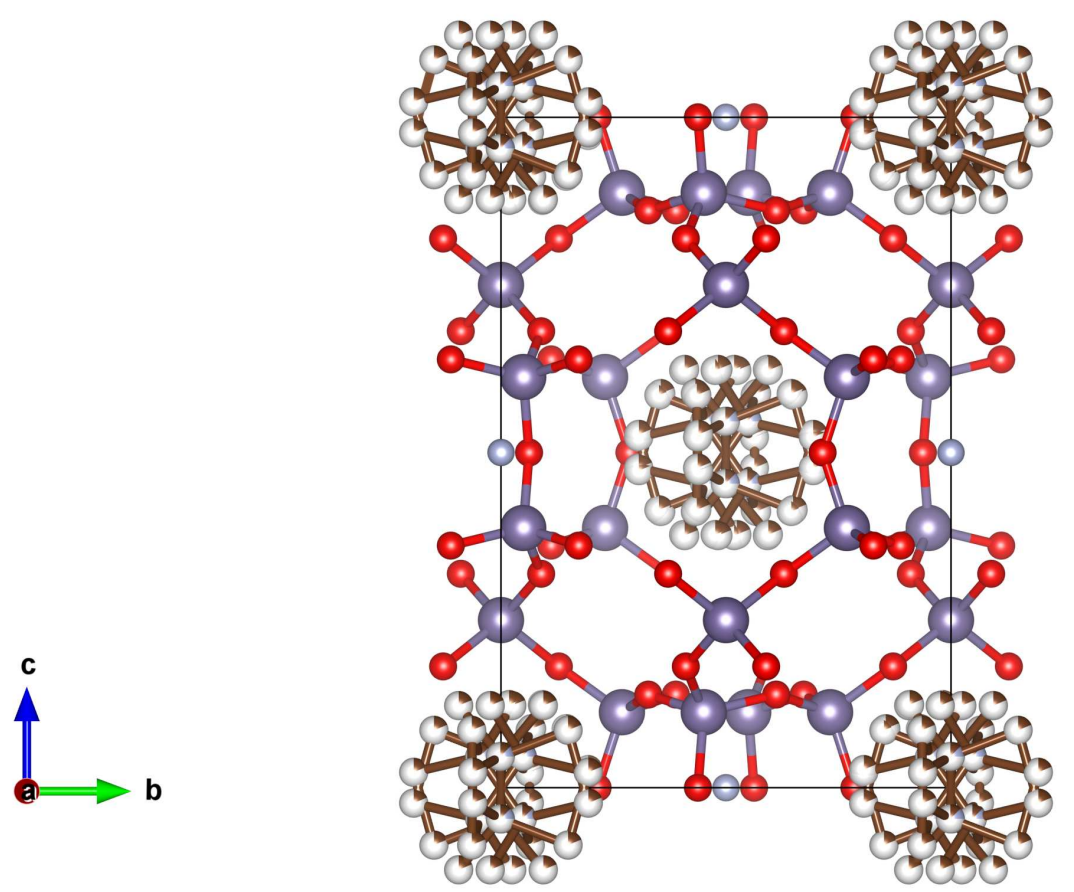

Figure S8: The structure ofTMTBA-containing $\mathrm{GeO}_{2}-\mathrm{AST}$ 


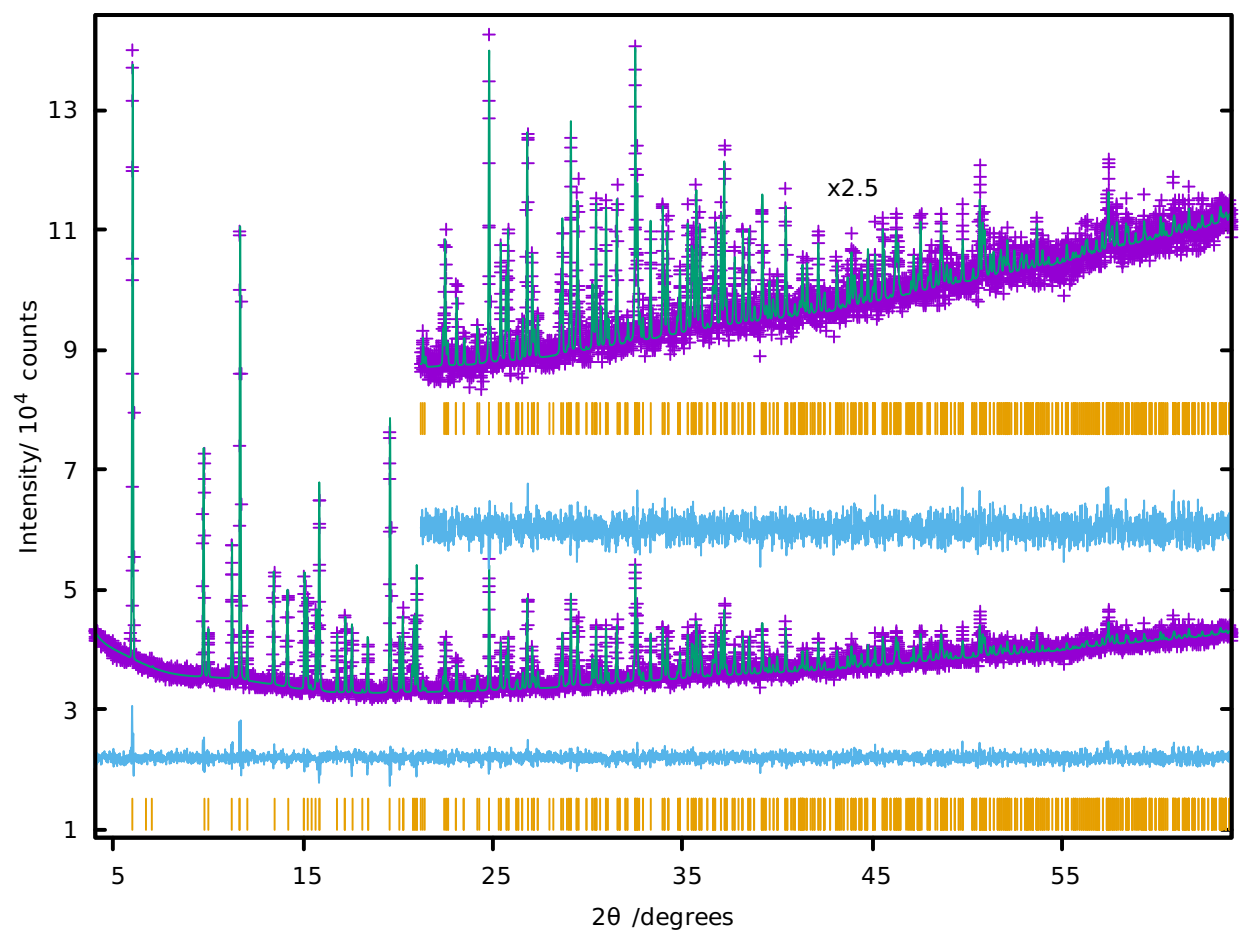

Figure S9: Rietveld plot for TBTMAF-containing $\mathrm{GeO}_{2}-\mathrm{AST}$. Experimental (crosses), calculated (solid line), and difference plot (lower trace). The tick marks represent the positions of allowed reflections $(\lambda=0.82548 \AA)$
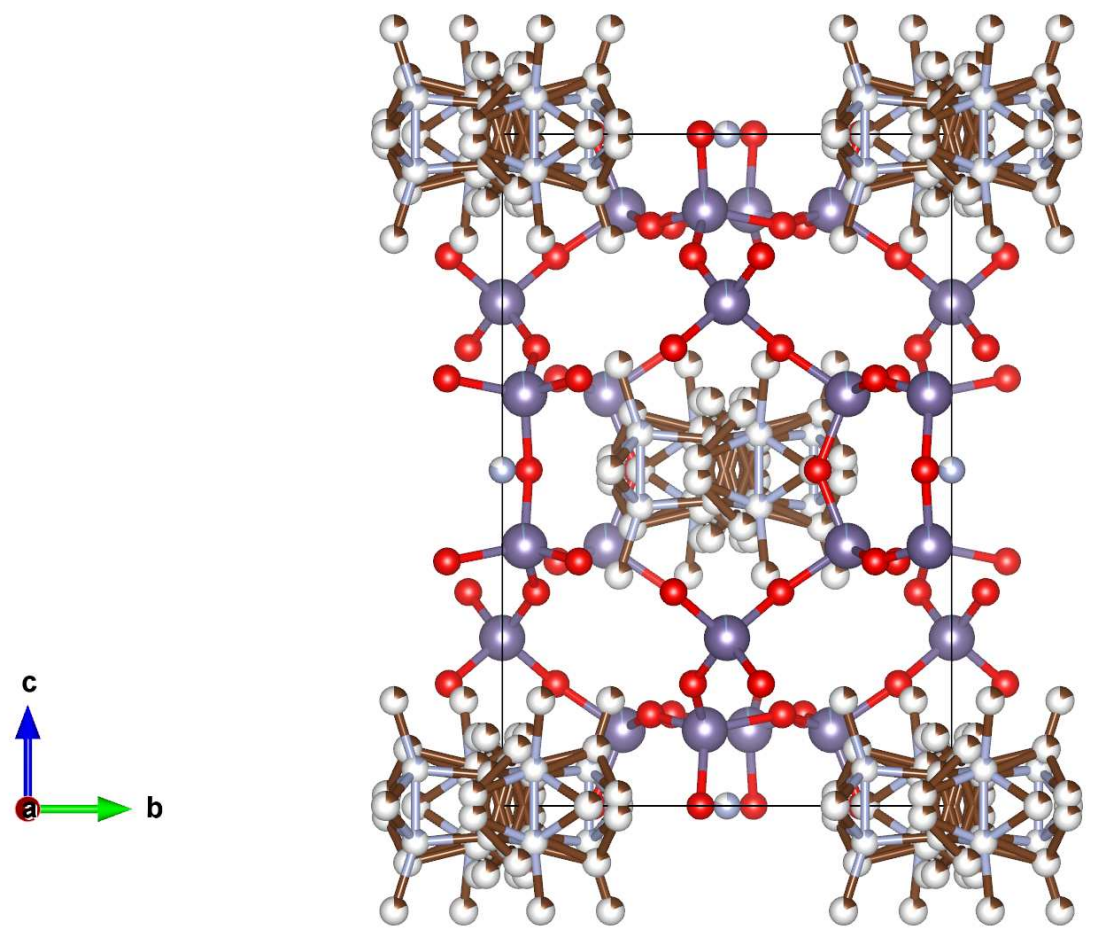

Figure S10: The structure ofTMTBA-containing GeAl9-1 


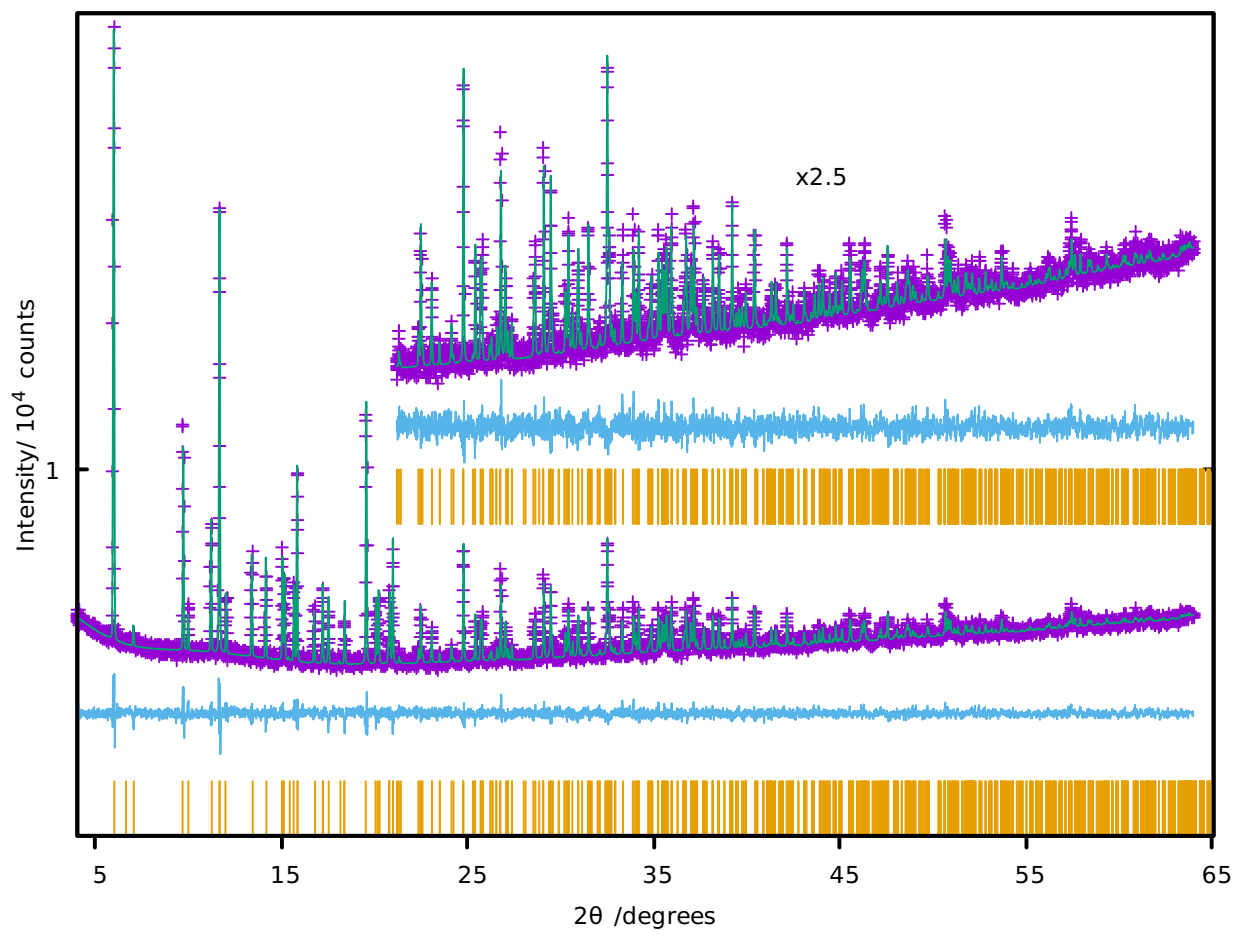

Figure S11: Rietveld plot for TMTBA-containing GeA19-1. Experimental (crosses), calculated (solid line), and difference plot (lower trace). The tick marks represent the positions of allowed reflections $(\lambda=0.82548 \AA)$

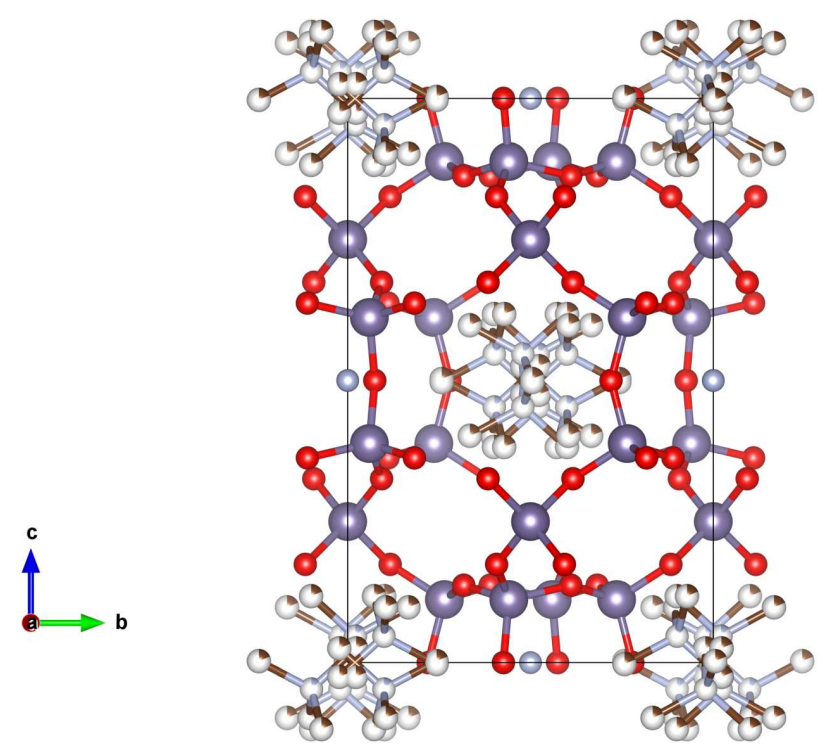

Figure S12: The structure of TMAF-containing GeAl9-30 


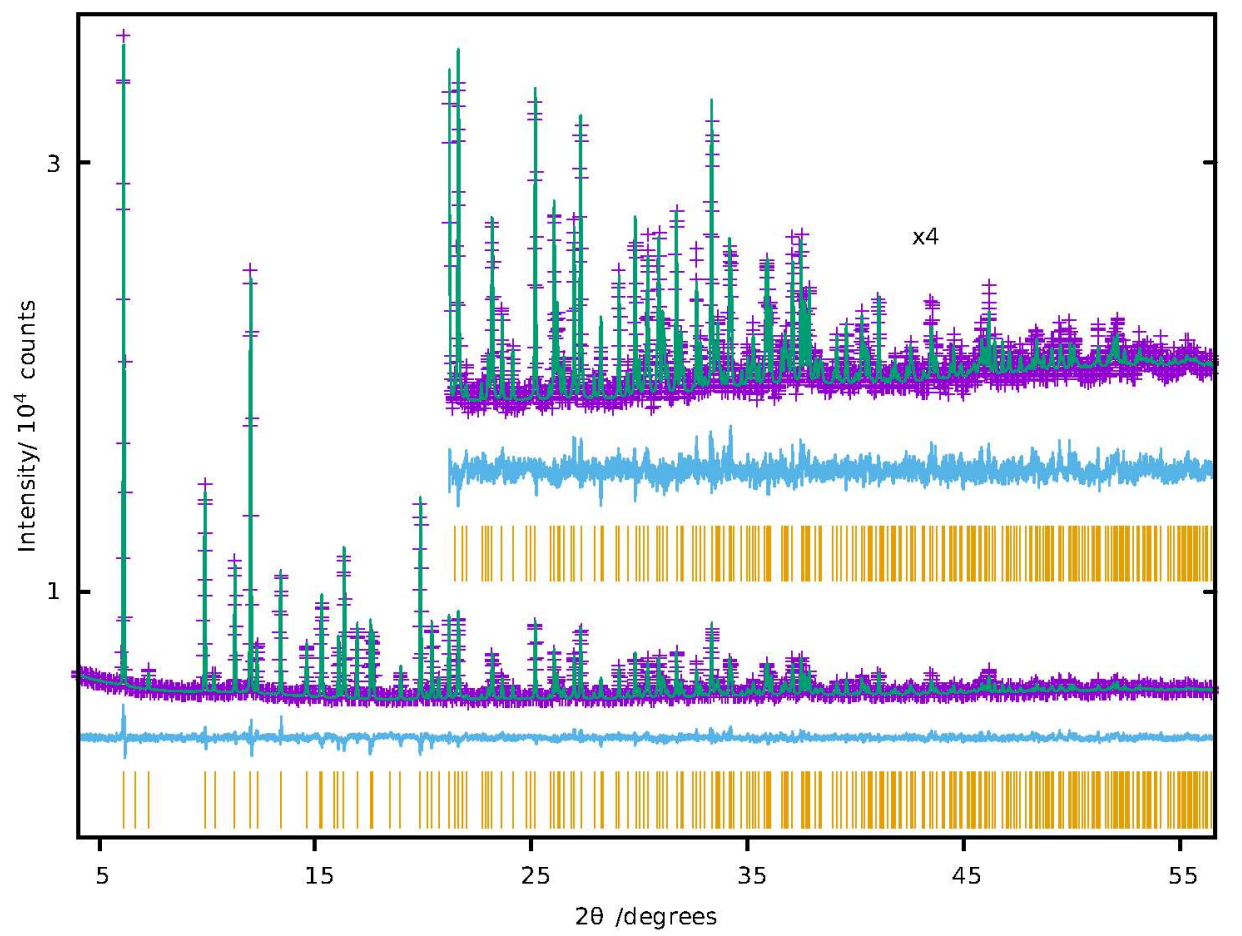

Figure S13: Rietveld plot for TMAF-containing GeAl9-30. Experimental (crosses), calculated (solid line), and difference plot (lower trace). The tick marks represent the positions of allowed reflections $(\lambda=0.82548 \AA)$

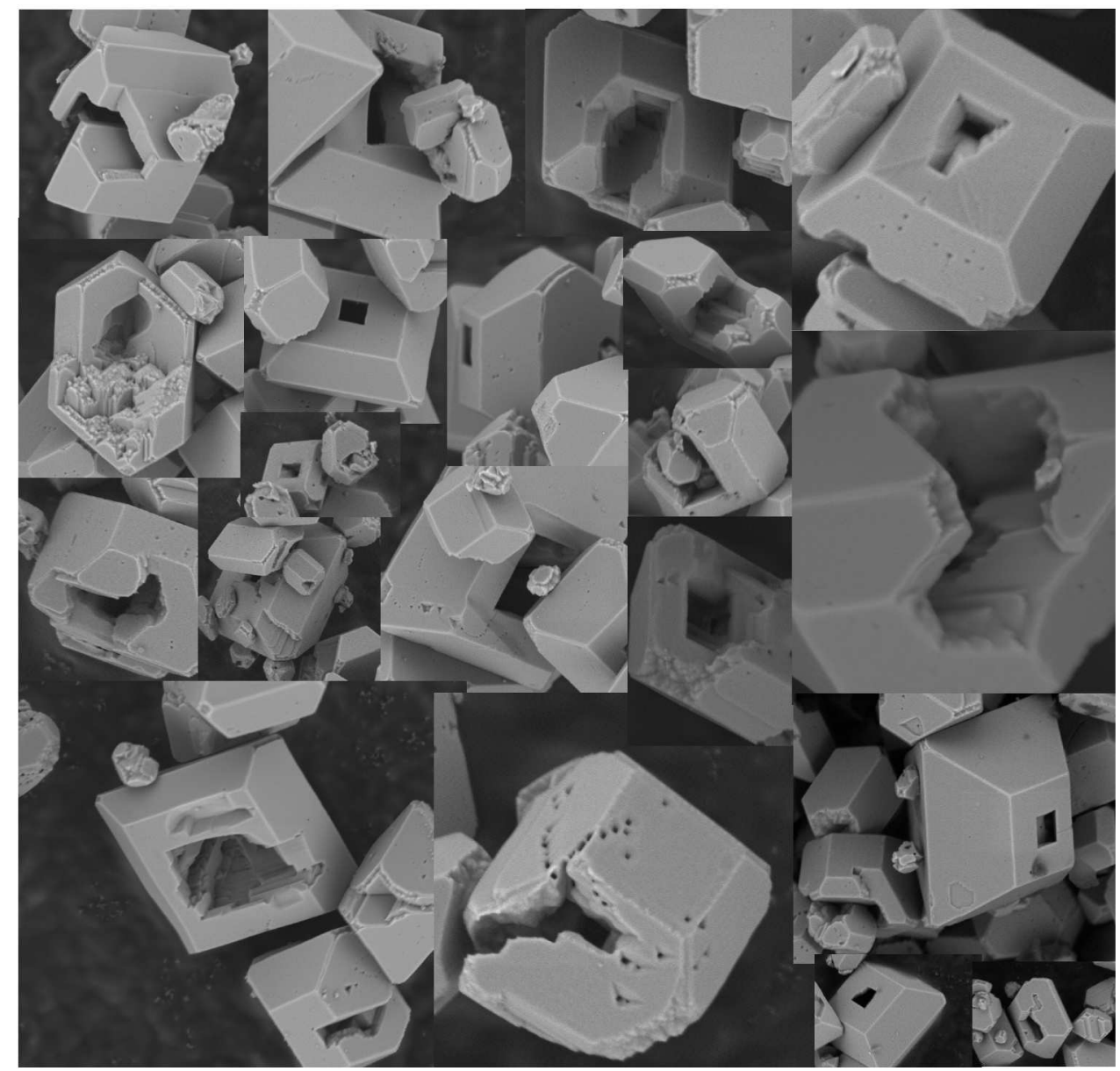

Figure S14: FE-SEM images of crystals of GeA19-30 that are either broken or properly oriented to show they are hollow. Please, note the very thick walls. 


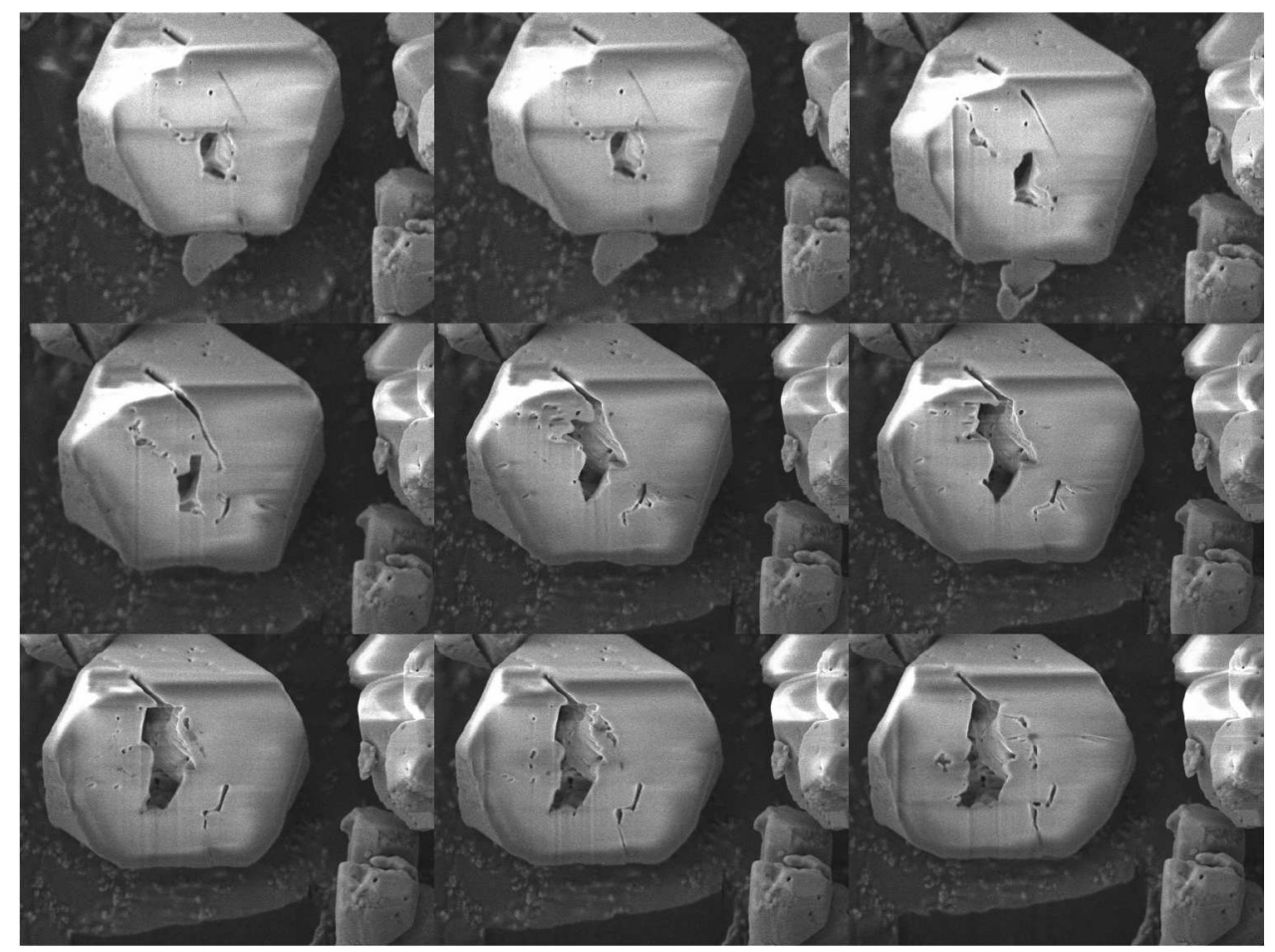

Figure S15: FE-SEM images of a crystal of GeAl9-30 after focused Ga ion bombardment (ZEISS AURIGA Compact). The sputtering level increases in the sequence of figures from left to right and from top to bottom.

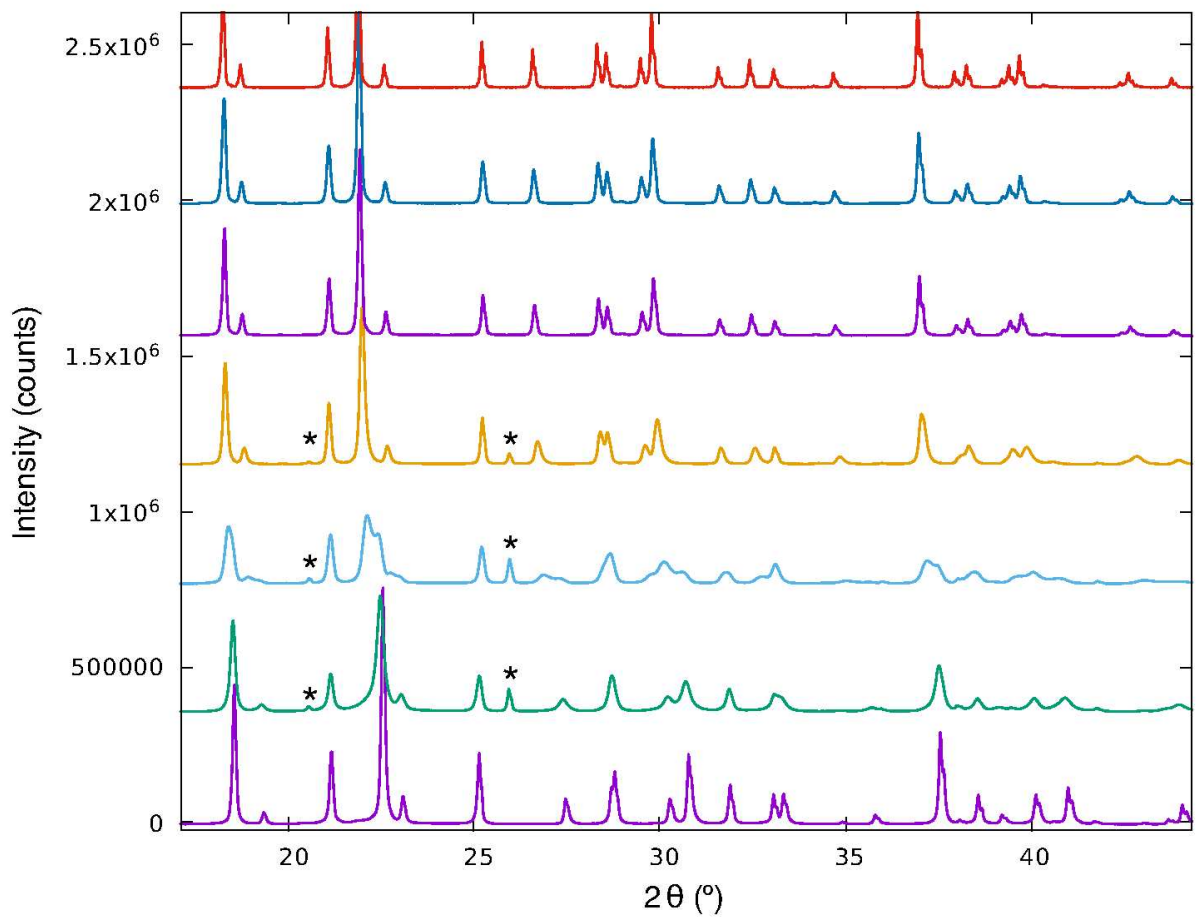

Figure S16: Powder XRD of $\mathrm{GeO}_{2}-\mathrm{AST}$ zeolites prepared from crystallization gels containing TMA/(TMA+TMTBA) molar fractions of (from bottom to top): $0.5,0.475,0.45,0.4,0.2,0.1$ and 0 , showing no phase seggregation occurred when TMA and TMTBA can simultaneously act as SDA. Weak reflections corresponding to quartz-like $\mathrm{GeO}_{2}$ impurities are marked with *. 


\section{References}

[1] L. A. Villaescusa, P. A. Barrett and M. A. Camblor, Chem. Mater., 1998, 10, 3966-3973.

[2] A. Larson and R. V. Dreele, General Structure Analysis System (GSAS), Los Alamos National Laboratory Report LAUR 86-748, 2004.

[3] R. B. Von Dreele, FPrime for Windows 1.0 for calculating real and anomalous dispersion coefficients, 1994.

[4] L. W. Finger, D. E. Cox and A. P. Jephcoat, J. Appl. Crystallogr., 1994, 27, 892-900. 